\title{
Letter-to-the-Editor
}

\section{Scalp Folliculitis with Demodex: Innocent Observer or Pathogen?}

\author{
Angel Fernandez-Flores ${ }^{1,3}$ and Antonio Alija ${ }^{2}$ \\ ${ }^{1}$ Anatomic Pathology and ${ }^{2}$ Dermatology, Hospital El Bierzo; ${ }^{3}$ Service of Cellular Pathology, Clinica Ponferrada; Ponferrada, Spain
}

We recently saw a case of an acute ulcerating folliculitis in a 75-year-old man, in which many Demodex sp. were found. Although the lesions were resistant to systemic conventional antibiotic therapy, they soon responded to topical permethrin plus oral metronidazole. This led us to consider that this mite has a pathogenic role, at least, in certain types of cutaneous pathology. After reviewing the literature, it seems that Demodex might be just an "innocent" observer in many cases, though it could play a pathogenic role under certain clinical conditions.

The patient, a 75-year-old male, came to the dermatology clinic, complaining of erythematous papules evolving into crusts, which he had suffered for eight years, with several episodes of varied intensity. The lesions were located in the scalp, the front side of the neck, the retroauricular area and the cheek. He had received oral treatment with several antibiotics (cefuroxyme, fuchsinic acid, and isothretinoin), with either only partial or no response at all. Laboratory cultures were negative for fungus, mycobacteria and common bacteria, except for Staphylococcus epidermidis, which was reported as a probable component of the normal flora.

The examination showed ulcerated lesions with an erythematous non-indurated border. The largest ulcer measured $6 \mathrm{~mm}$ in diameter (Figure 1). When the lesions regressed, they left whitish depressed scars.

A biopsy of one of the scalp lesions was performed, showing an intense acute folliculitis with ulceration of the skin in some areas. Many Demodex-type arthropods were evident in the inflammatory infiltrate, as well as inside the follicles that were immersed in the infiltrate, next to the infiltrate or close to the infiltrate (Figure 2). We, therefore, established a diagnosis of folliculitis by Demodex. We also used special staining, including periodic acid Schiff (PAS) reaction, Giemsa and Ziehl-Neelsen, with no evidence of fungi or microorganisms. The PAS technique contributed, nevertheless, as it allowed us to identify the Demodex organisms (Figure 2).

Treatment with topical permethrin plus oral metronidazole was established, and a good response was obtained within a few days, with clearance of the lesions. Seven months later, the patient was free of disease.

Received on 19 September 2008; revised 18 December 2008. Address for correspondence: Dr. Angel Fernandez-Flores, MD, PhD. S. Patología Celular, Clínica Ponferrada. Avenida Galicia 1. Zip code: 24400. Ponferrada, Spain. Telephone: (00 34) 9874237 32. Fax: (00 34) 9874291 02. E-mail: gpyauflowerlion@terra.es.

The Brazilian Journal of Infectious Diseases

2009;13(2):81-82. (C) 2009 by The Brazilian Journal of Infectious Diseases and Contexto Publishing. All rights reserved.
The mite Demodex (Demodecidae) [1] is commonly present in folliculosebaceous units of nearly everyone older than 10 years old [1-5]. In humans, two different species have been found: $D$. folliculorum, which is present in the infundibulum, and $D$. brevis, which inhabits the sebaceous glands as well as the meibomian glands $[3,4,6,7]$.

Demodex is usually a saprophyte on humans, feeding from gland secretions [4], and causing no symptoms [3].

Nevertheless, $D$. folliculorum has also been associated with varied cutaneous pathologies [8], such as rosacea [1,9-14], granulomatous peri-oral dermatitis [15], blepharytis [1,16,17], inflammatory nodules [1], and pustular folliculitis [8,9,18,19].

Since Demodex is a saprophyte in the human skin, a causal relationship with those pathologies has always been controversial $[8,20,21]$. Nevertheless, some studies have demonstrated an association between Demodex and follicular inflammation [22]. This is also supported by the fact that the symptoms are clearly reduced when this parasite is correctly treated [8-10,14,17,23-27]. On the other hand, some symptoms persist when only antibacterial therapeutic agents are used [14]. In some cases, therapy with metronidazole was not successful [28], which supports an etiological role of Demodex in certain cutaneous pathologies. Although some authors have demonstrated the presence of a high density of Demodex in common rosacea [18,29], the latter usually responds to Metronidazole, with clearance of the symptoms, even if the number of Demodex persists [30]. We could then assume that in certain cutaneous pathologies, Demodex acts as an innocent observer rather than a pathogen.

There has been some speculation about the clinical differences between the two types of rosacea $[10,29]$; on one hand, the one which is associated with Demodex as a causal agent presents a "dry" eruption [10], with follicular scaling, vesicles and pustules. On the other hand, the common rosacea usually presents an oily skin, without scales, and the pustules and papules appear inflamed [28].

Some authors have indicated two main conditions that have to be met before Demodex can be considered as a pathogen in a biopsy: an abnormal number of mites, or their presence in an abnormal place, i.e., the dermis [22,28,30]. For instance, more than five Demodex per square centimeter has been suggested as an abnormal condition [31]. Considering this, Demodex could be in fact, pathogenic, not only in the dry variant of rosacea, but also in some cutaneous disorders that present with non-classic signs and symptoms, such as facial itch, with or without erythema, or as non-specific pitiriasiform scaly pruriginous lesions [31].

On the other hand, Demodex might be a mere "observer" in other types of more classic conditions in which many studies have failed to connect the mite with pathology $[4,20,32,33]$. 
Figure 1. Ulcerated lesion of the scalp (top) and a crusted lesion of the retroauricular area (bottom left). When regressing, some of the lesions left a whitish scar (bottom right).
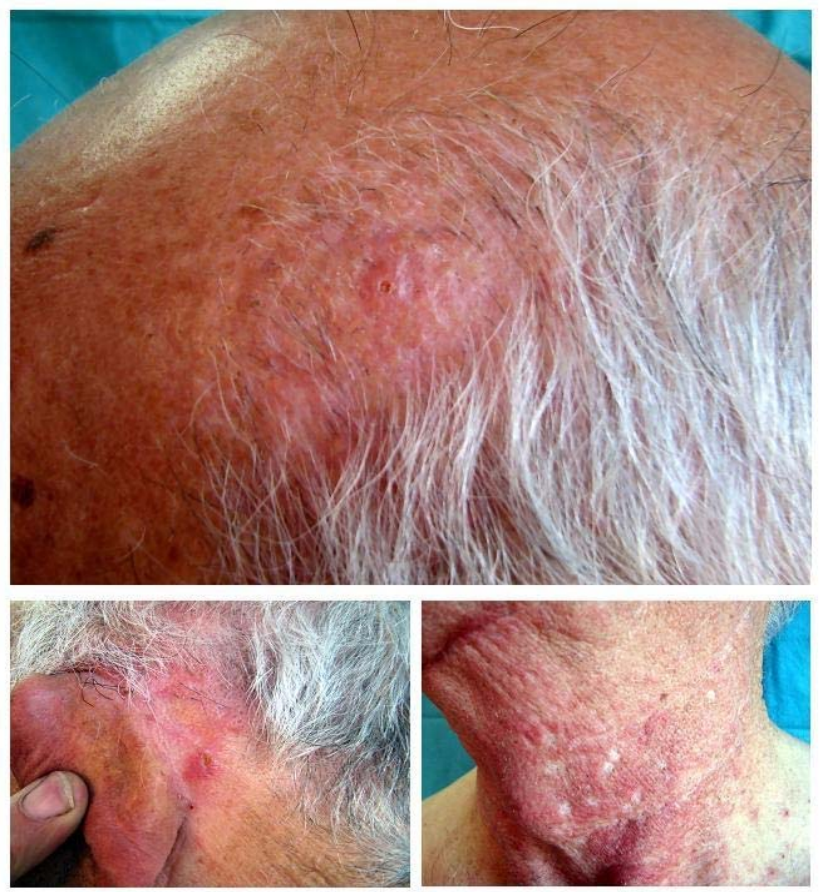

\section{References}

1. Forton F. Démodex et inflammation périfolliculaire chez l'homme : revue et observation de 69 biopsies. Ann Dermatol Venereol 1986; $113: 1047-58$.

2. Du Bois A. Recherche du Demodex folliculorum hominis dans la peau saine. Ann Derm Syph 1910;1:188-90.

3. Norn M.S. Demodex folliculorum. Incidence, regional distribution, pathogenicity. Dan Med Bull 1971;18:14-7.

4. Nutting W.B. Hair follicle mites (Acari: Demodicidae) of man. Int J Dermatol 1976;15:79-98.

5. Burns D.A. Follicle mites and their role in disease. Clin Exp Dermatol 1992;17:552-5.

6. English F.P., Nutting W.B. Demodicidosis of ophtalmic concern. Am J Ophthalmol 1981;91:362-72.

7. Aydogan K., Alver O., Tore O., Karadogan S.K. Facial abscess-like conglomerates associated with Demodex mites. JEADV 2006;20:999-1032.

8. Purcell S.M., Hayes T.J., Dixon S.L. Pustular folliculitis associated with Demodex folliculorum. J Am Acad Dermatol 1986;15:1159-62.

9. Miskjian H.G. Demodicidosis. Demodex infestation of the scalp. Arch Dermatol Syph 1951;63:282-3.

10. Ayres S. Jr., Ayres S. III. Démodé tic eruptions (Demodicidosis) in the human. Arch Dermatol 1961;83:816-827.

11. Grosshans E., Dungler T., Kien T.T., Kremer M. Demodex folliculorum und Rosacea: experimentelle und immunologische Studien. Z Hautkr 1980;55:1211-8.

12. De Dulanto F., Camacho-Martínez F. Demodicidose "gravis". Ann Dermatol Venereol 1979;106:699-704

13. Georgala S., Katoulis A.C., Kylafis G.D., et al. Increase density of Demodex folliculorum and evidence of delayed hypersensitivity reaction in subjects with papulopustular rosacea. J Eur Acad Dermatol Venereol 2001;15:441-4.

14. Sanfilippo A.M., English III J.C. Resistant scalp folliculitis secondary to Demodex infestation. Cutis 2005;76:321-4.

15. Ecker R.I., Winkelmann R.K. Demodex granuloma. Arch Dermatol 1979; $115: 343-4$.

16. Ayres S. Jr., Mihan R. Rosacea-like demodicidosis involving the eyelids. Arch Dermatol 1967;95:63-6.
Figure 2. Cutaneous biopsy. Several images of Demodex can be seen, either immersed in the infiltrate (top left: transverse section of the microorganism), in the follicles that were immersed in the infiltrate (top right), in the follicles next to the infiltrate (bottom right), or in the follicles that were close to the infiltrate (bottom left). Periodic acid Schiff reaction did not show fungi, but was useful to show the Demodex organisms (top right).
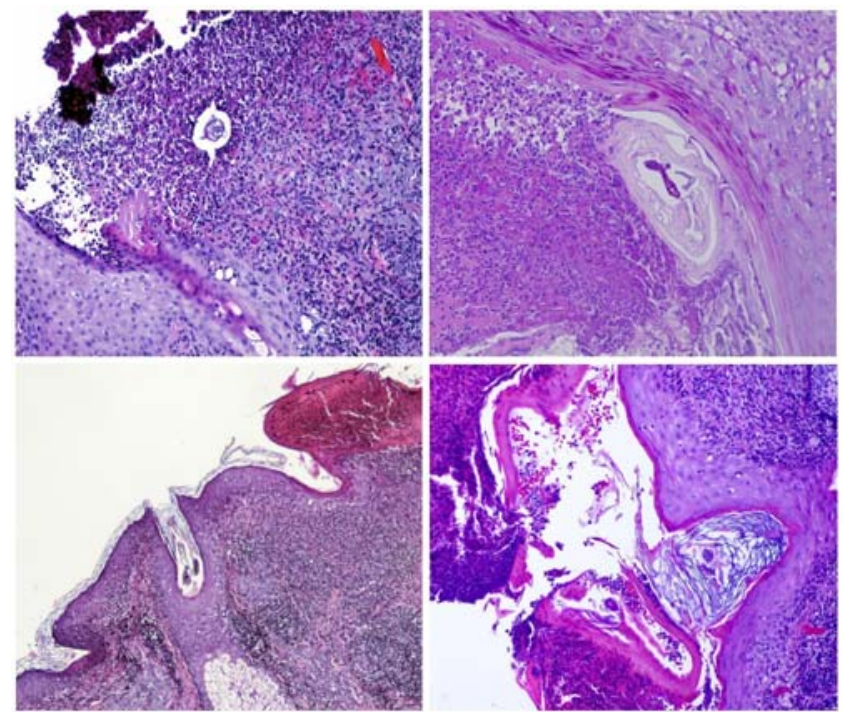

17. Smith S., McCulloch C. Demodex folliculorum palpebrarum. Can J Ophthalmol 1969;4:3-15.

18. Forton F., Seys B. Density of Demodex folliculorum in rosacea: a case-control study using standarized skin-surface biopsy. Br J Dermatol 1993;128:650-9.

19. Grossmann B., Jung K, Linse R. Tubero-pustular demodicosis. Hautarzt 1999; 50: 491-4.

20. Marks R., Harcourt-Webster J.N. Histopathology of rosacea. Arch Dermatol 1969;100:683-91.

21. Aylesworth R., Vance J.C. Demodex folliculorum and Demodex brevis in cutaneous biopsies. J Am Acad Dermatol 1982;7:583-9.

22. Vollmer R.T. Demodex-associated folliculitis. Am J Dermatopathol 1996; $18: 589-91$.

23. Hoekzema R., Hulsebosch H.J., Bos J.D. Demodicidosis or rosacea: what did we treat? Br J Dermatol 1995;133:294-9.

24. Meinking T.L., Taplin D., Hermida J.L., et al. The treatment of scabies with ivermectin. N Engl J Med 1995;333:26-30.

25. Nakagawa T., Sasaki M., Fujita K., et al. Demodex folliculitis on the trunk of a patient with mycosis fungoides. Clin Exper Dermatol 1996;21:148-50.

26. Schaller M., Sander C.A., Plewig G. Demodex abscesses: clinical and therapeutic challenges. J Am Acad Dermatol 2003;49:S272-S274.

27. Allen K.J., Davis C.L., Billings S.D., Mousdicas N. Recalcitrant papulopustular rosacea in an immunocompetent patient responding to combination therapy with oral Ivermectin and topical Permethrin. Cutis 2007;80:149-51.

28. Pallotta S., Cianchini G., Martelloni E., et al. Unilateral demodicidosis. Eur J Dermatol 1998;8:191-2.

29. Bonnar E., Eustace P., Powell F.C. The Demodex mite population in rosacea. J Am Acad Dermatol 1993;28:443-8.

30. Shelley W.B., Shelley E.D, Burmeister V. Unilateral demodectic rosacea. J Am Acad Derm 1989;20:915-7.

31. Karincaoglu Y., Bayram N., Aycan O., Esrefoglu M. The clinical importance of demodex folliculorum presenting with nonspecific facial signs and symptoms. J Dermatol 2004;31:618-26.

32. Robinson T.W.E. Demodex folliculorum and rosacea. Arch Dermatol 1965;92:542-4.

33. Roth A.M. Demodex folliculorum in hair follicles of eyelid skin. Ann Ophthalmol 1979;11:37-40. 